\title{
Creating Reactivity with Unstable Endmembers using Pressure and Temperature: Synthesis of bulk cubic $\mathrm{Mg}_{0.4} \mathrm{Fe}_{0.6} \mathrm{~N}^{\star *}$
}

\author{
George Serghiou, ${ }^{*}$ Gang Ji, Nicholas Odling, Hans J. Reichmann, Jean-Paul Morniroli, Reinhard \\ Boehler, Dan J. Frost, Jonathan P. Wright, Bernd Wunder
}

\begin{abstract}
Alloy and nitride solid solutions are prominent for structural, energy and information processing applications. There are frequently however barriers to making them. We remove barriers to reactivity here using pressure with a new synthetic approach. We target pressures where the reasons for cubic endmember nitride instability can become the driving force for cubic nitride solid solution stability. Using this approach we form a novel rocksalt $\mathrm{Mg}_{0.4} \mathrm{Fe}_{0.6} \mathrm{~N}$ solid solution at between 15 and $23 \mathrm{GPa}$ and up to $2500 \mathrm{~K}$. This is a system where, neither an alloy nor a nitride solid solution form at ambient conditions and bulk $\mathrm{MgN}$ and FeN endmembers do not form, either at ambient or at high pressure. The new nitride is formed, by removing endmember lattice mismatch with pressure, allowing a stabilizing redistribution of valence electrons upon heating. This approach can be employed for a range of normally unreactive systems. $\mathrm{Mg}, \mathrm{Fe}$ and enhanced nitrogen presence, may also indicate a richer reaction chemistry in our planets interior.
\end{abstract}

A pivotal attribute to preparing sought-after materials and materials landscapes is reactivity. Structural and electronic incompatibility is a central barrier to creating solid solution chemistry in particular. An accompanying principal challenge is to have control over what structure is formed. In a solid solution this can be dictated by the crystal structure of the endmembers, as seen for example in well recognized solid solutions ${ }^{[1]}$ such as GaN-AIN, $\quad \mathrm{Al}_{2} \mathrm{O}_{3}-\mathrm{Cr}_{2} \mathrm{O}_{3}$ or $\mathrm{Si}-\mathrm{Ge}$ leading to profound applications. ${ }^{[2]}$ What happens however when starting materials are unreactive, and endmembers dictating formation of wanted structures in solid solution do not exist? Here by using pressure, with a novel approach, we both remove ambient constraints to

[a*] Dr. G. Serghiou

School of Engineering, University of Edinburgh

Kings Buildings, Mayfield Road, EH9 3FB, Edinburgh, UK

Email: george.serghiou@ed.ac.uk

homepage: http://www.homepages.ed.ac.uk/gserghio/

[b] Dr. G. Ji

Unité Matériaux et Transformations, UMR CNRS 8207, Université

Lille 1, Villeneuve d'Ascq, 59655 Lille, France

[c] Dr. N. Odling

School of Geosciences, The Grant Institute, University of Edinburgh,

Kings Buildings, West Mains Road, EH9 3JW, Edinburgh, UK

[d] Dr. H. J. Reichmann, Dr. Bernd Wunder

Helmholtz-Zentrum Potsdam, German Research Centre for

Geosciences, Telegrafenberg, 14473 Potsdam, Germany

[e] Professor J.-P. Morniroli

Université Lille 1 and Ecole Nationale Supérieure de Chimie de Lille, Villeneuve d'Ascq, 59655 Lille, France

[f] Dr. R. Boehler

Geophysical Laboratory, Carnegie Institution of Washington, Washington, DC 20015, USA

[g] Professor Dan J. Frost

Bayerisches Geoinstitut, Universität Bayreuth, D-95540, Bayreuth, Germany

[h] Dr. J. P. Wright

European Synchrotron Radiation Facility, F-38043 Grenoble, France

Supporting information for this article is given via a link at the end of the document. reactivity and stabilize a targeted crystal symmetry in solid solution, not stable at endmember composition. We focus on magnesium-iron-nitride, a system whose formation would have crystal chemical, technological and planetary science impact.

Magnesium ( $\mathrm{Mg}$ ) and Iron ( $\mathrm{Fe})$, uniquely, are principal components of virtually all phases of our planet's interior. Their intrinsic importance is hence, that they are a predominant part of our planet's chemical backbone (Mg, Fe mantle; Fe core) ${ }^{[3]} \mathrm{A}$ principal technological importance of $\mathrm{Fe}$ is that it is the dominant component of structural materials. ${ }^{[4]} \mathrm{A}$ principal technological importance of $\mathrm{Mg}$ is that it is the lightest metal employed in structural materials. ${ }^{[5]}$ Thus, combining Mg with heavier metals, has significant structural (ex. automotive, mobile electronics), ${ }^{[6]}$ energetic (ex. portability, hydrogen storage) $)^{[5,7]}$ and biomechanical (ex. orthopaedics, scaffolds) ${ }^{[8]}$ advantages. A MgFe alloy cannot be synthesized at ambient pressure, due mostly to an almost $30 \%$ atomic radius difference between the two. ${ }^{[9,10]}$ Pressure however can have a profound effect on reactivity, but well over a million atmospheres are required to dissolve 10 atom $\% \mathrm{Mg}$ in $\mathrm{Fe}^{[11]} \mathrm{A}$ combination of high pressure and nitrogen incorporation, may facilitate solid solution formation between metals that are otherwise unreactive at ambient and at high pressure. ${ }^{[12]} \mathrm{A}$ particular nitride synthesis incentive is due to an intriguing potential application for rocksalt $\mathrm{MgN}$ and $\mathrm{FeN}$, in spintronics, where electron spin is exploited for information processing and storage. ${ }^{[13,14]}$ The challenge is however that rocksalt $\mathrm{Mg}-\mathrm{N}$, analogous to bulk $\mathrm{Fe}-\mathrm{N}$, has no stability field either at ambient or at high pressure. ${ }^{[15-17]}$ Iron nitrides, namely, both at ambient and at high pressures and temperatures, only form interstitial structures ranging from $\mathrm{Fe}_{4} \mathrm{~N}$ to $\mathrm{Fe}_{3} \mathrm{~N}_{\mathrm{x} \leq 1.5}$ and only thin film, but no bulk iron nitride phase forms at higher $\mathrm{N}$ concentrations. ${ }^{[13,15,17]}$ No rocksalt $\mathrm{Mg}-\mathrm{N}$ forms and magnesium nitride adheres to standard salt-like $\mathrm{Mg}_{3} \mathrm{~N}_{2}$ stoichiometry, both at ambient and at high pressure. ${ }^{[16]} \mathrm{No} \mathrm{Mg}-\mathrm{Fe}$ nitride structure forms at ambient pressure either. We target integration of $\mathrm{Mg}$, $\mathrm{Fe}$ and nitrogen in the rocksalt structure, through synthesis of a $\mathrm{Mg}$-Fe nitride solution using pressure. However previous routes to particular solid solution structure by reacting accessible likeendmember structures cannot be adopted here.

Here we employ pressure without access to endmember structures, requiring hence a different approach to previously, in order to create reactivity and prepare a novel nitride with the cubic rocksalt structure. We target namely pressures where the reasons for cubic endmember nitride instability can become the driving force for cubic nitride solid solution stability. To do this we identify why the rocksalt endmember nitride structures are unstable and how their instabilities can be exploited to their mutual benefit using pressure. Rocksalt FeN would have 13 valence electrons. For binary rocksalt transition-metal nitrides, a total of 13 valence electrons and upwards would generally necessitate placement of electrons in energetically unfavorable antibonding bands making these structures unstable. ${ }^{[18]}$ Rocksalt $\mathrm{MgN}$ on the other hand would only provide 5 valence electrons, but 6 are required to fill the bonding state and stabilize the 
structure. ${ }^{[19]}$ Hence a rocksalt $\mathrm{Mg}_{\mathrm{x}} \mathrm{Fe}_{1-\mathrm{x}} \mathrm{N}$ solid solution could be stabilized by a transfer of electrons from energetically highly unfavorable antibonding states in $\mathrm{Fe}$ to energetically favorable bonding states that are empty in $\mathrm{Mg}^{[19]}$ For this stabilizing transfer to be made possible though, requires first, communication, that is, a lattice parameter compatibility between $\mathrm{FeN}$ and $\mathrm{MgN}$. Indeed, nitride rocksalt solid solution studies demonstrate that similar endmember lattice parameters are principal for solid solution formation. ${ }^{[20]}$ However, calculated ambient pressure lattice constants of rocksalt $\mathrm{MgN}$ and FeN of a $=4.45 \AA$ and $3.96 \AA$ respectively,${ }^{[13,19]}$ involve a destabilizing $12.4 \%$ lattice mismatch. ${ }^{[20]}$ Nevertheless, rocksalt $\mathrm{MgN}$ is calculated to be about 3 times more compressible than FeN, hence at high pressure their lattice constant mismatch would be smaller. ${ }^{[13,19]}$ For reference, experiments show $\mathrm{Mg}$ to be about 4 times more compressible than $\mathrm{Fe}$, facilitating, an atomic radius difference decrease by $30 \%$ at $15 \mathrm{GPa}^{[10]}$ Hence, here, by applying pressure to $\mathrm{Mg}, \mathrm{Fe}$ and nitrogen, the structural mismatch constraint to reactivity may be lifted, which concomitantly allows electronic constraints on forming endmember rocksalt $\mathrm{MgN}$ and $\mathrm{FeN}$ to be ameliorated by electron transfer from $\mathrm{Fe}$ to $\mathrm{Mg}$ stabilizing the $\mathrm{Mg}_{\mathrm{x}} \mathrm{Fe}_{1-\mathrm{x}} \mathrm{N}$ rocksalt solid solution upon heating. For the high pressure experiments we employ both laser-heated diamond anvil cell and multianvil methods for synthesis at between 15 and $23 \mathrm{GPa}$ and up to $2500 \mathrm{~K}$, in conjunction with precession electron diffraction, scanning and field emission scanning electron microscopy and synchrotron angle dispersive X-ray diffraction with simultaneous microfluorescence for high resolution structural, chemical and morphological characterization of the reaction products. ${ }^{[21]}$ (see also Supporting Information containing more detailed experimental description)

Figure 1a shows a scanning electron microscopy image of a recovered polished section of a magnesium iron nitride sample synthesized at $15 \mathrm{GPa}$. The lighter strips are from a sodium magnesium iron nitride phase that also arises in the multianvil synthesis due to the sodium in the nitrogen providing source. Figure $1 \mathrm{~b}$ is a transmission electron microscopy image of a

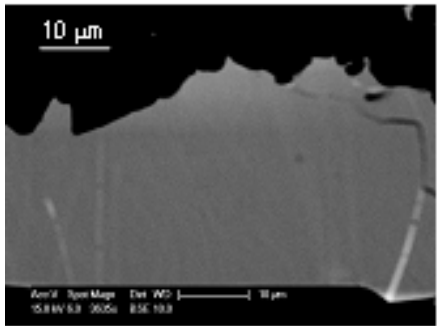

a

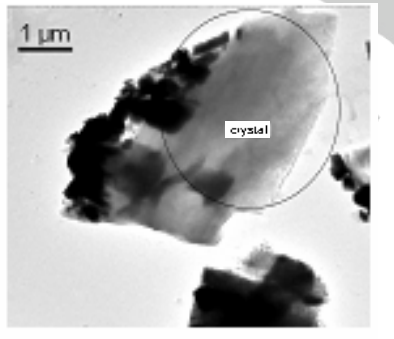

$\mathrm{b}$
Figure 1. Backscattered scanning electron microscopy (BSE) image of a polished magnesium iron nitride section (a) and bright field transmission electron microscopy image of a magnesium iron nitride crystal in a TEM grid (b), from multianvil synthesis at $15 \mathrm{GPa}$ and $1800 \mathrm{~K}$, followed by temperature, and subsequent pressure quenching.

magnesium iron nitride crystal in a TEM grid. Optical images of an $\mathrm{Mg}$-Fe pellet in a nitrogen pressure medium before and after laser-heating are shown in figures $2 \mathrm{a}$ and $2 \mathrm{~b}$ respectively. Examples of chemical analyses of the magnesium iron nitride phase taken from the recovered polished multianvil sample using scanning electron microscopy and from a diamond anvil cell recovered sample using transmission electron microscopy are shown in figures $3 a, b$ respectively. To investigate the

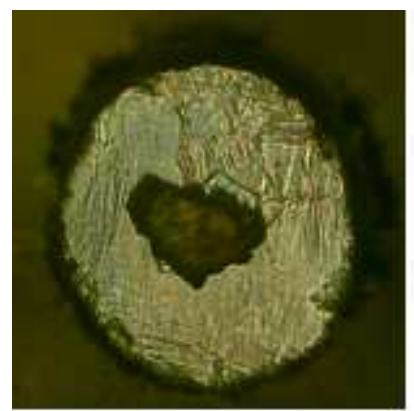

a

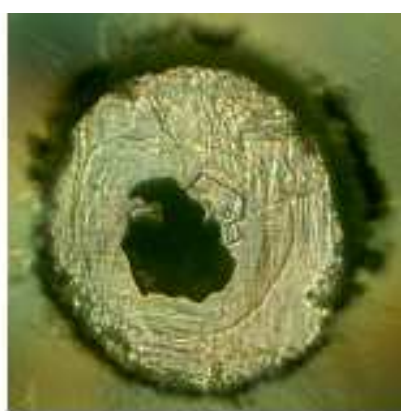

b
Figure 2. View through a diamond into the $140 \mu \mathrm{m}$ diameter laser-drilled tungsten hole containing an FeMg pressed pellet placed on an $\mathrm{Al}_{2} \mathrm{O}_{3}$ polished plate in a nitrogen pressure medium, before laser-heating (a) and after laserheating (b) with distinctly visible, recrystallized nitrogen from the melt, after heating at $23 \mathrm{GPa}$ to $2500 \mathrm{~K}$.

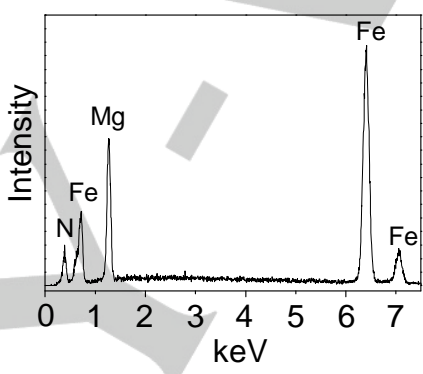

a

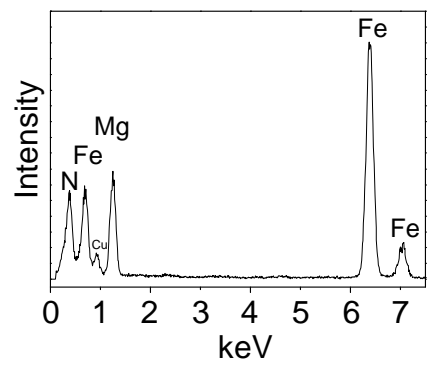

b
Figure 3. Examples of SEM/EDX and TEM/EDX chemical analyses obtained at ambient conditions after high pressure and temperature syntheses revealing a $\mathrm{Mg}_{0.4} \mathrm{Fe}_{0.6} \mathrm{~N}$ stoichiometry. (a) Semi-quantitative SEM EDX analysis from a polished section from multianvil synthesis $\left(1 \sigma_{\mathrm{Fe}}: 0.03 ; 1 \sigma_{\mathrm{Mg}}: 0.02 ; 1 \sigma_{\mathrm{N}}: 0.04\right)$ and (b) TEM/EDX from a crystal from diamond anvil synthesis. The new crystal phase is stable for a wider range of stoichiometries based on measurements from individual crystallites using TEM. The Cu peak originates from the Cu grid of the TEM sample holder. Further chemical analysis based on SEM/EDX, wavelength dispersive spectrometry (WDS), Vegards law, occupancies from Rietveld refinement and TEM/EDX is provided in the Supporting Information.

structure numerous single crystallites were analyzed using precession electron diffraction. Two single crystal diffraction patterns from the multianvil reaction product and two from the laser-heated diamond anvil cell reaction product are shown in Figures $4 a-d$ respectively. These are indexed to the cubic rocksalt $F m 3 m$ structure. An XRD pattern from a sample extracted from a pellet, also indexed to the cubic rocksalt $F m 3 m$ structure with the bulk $\mathrm{Mg}_{0.4} \mathrm{Fe}_{0.6} \mathrm{~N}$ composition, is shown in Figure 5. In contrast to the 15 to $23 \mathrm{GPa}$ experiments, in an ambient and four lower pressure experiments to $3 \mathrm{GPa}$ and $1500 \mathrm{~K}$ on magnesium, iron, iron nitride, nitrogen and sodium azide containing mixtures (see also Supporting Information containing more detailed experimental description) using tube furnace, piston cylinder ${ }^{[22]}$ (Helmholtz Centre Potsdam) and MAX80 press $^{[23]}$ (DESY Deutsches Elektronen 


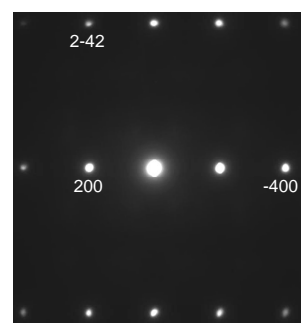

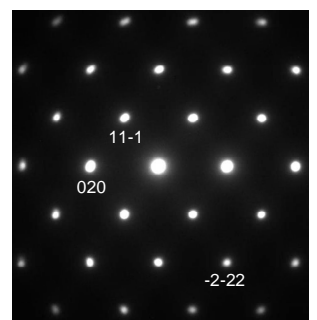

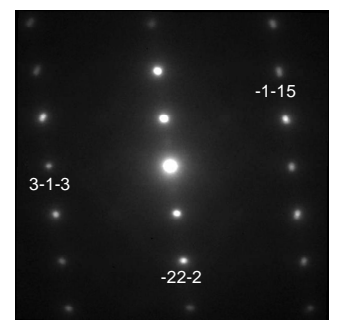

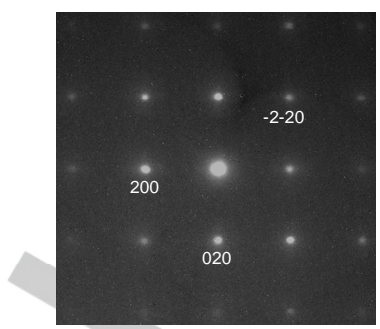

d

Figure 4. PED zone axis patterns of magnesium iron nitride crystals with space group $F m \overline{3} m$ : (a and b) of the [012] and [101] zone axes respectively from multianvil and ( $c$ and d) of the [231] and [001] zone axes respectively from diamond anvil syntheses. The match between the experimental and simulated rocksalt zone-axis diffraction patterns with kinematic intensities is provided in the Supporting Information.

Synchrotron, Hamburg) devices, only iron, iron nitride, magnesium, magnesium nitride and magnesium oxide result.

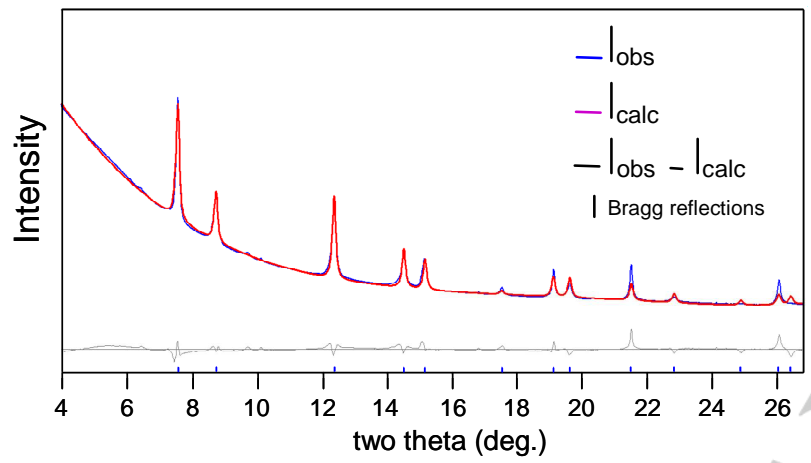

Figure 5. XRD pattern of the $\mathrm{Mg}_{0.4} \mathrm{Fe}_{0.6} \mathrm{~N}$ composition with $\mathrm{Fm} 3 \mathrm{~m}$ space group $[\mathrm{a}=4.1796(2) \AA]$, and a calculated density of $5.189 \mathrm{~g} / \mathrm{cm}^{3}$. A 0.31849 $\AA$ x-ray wavelength was employed. Detailed results of the Rietveld refinement are provided in the supplementary information. Agreement factors are $R_{\exp }$ : 3.01, $R_{B}: 2.251, R_{p}: 1.80, R_{w p}: 2.95$. The bulk composition based on SEM/EDX/WDS, Vegards law analysis and the occupancies from the Rietveld refinement are in good agreement. This analysis is presented in the supplementary information. Preferred orientation and potentially local chemical variation can affect relative $x$-ray diffraction intensities. In this context, further $\mathrm{x}$-ray diffraction and tabulated observed integrated intensity data and a texture magnitude value are also presented in the Supporting Information. In conjunction with this, schematics of the sample processing and diffraction geometry and set-up for the x-ray diffraction measurements are also presented in the Supporting Information.

The materials chemistry design methodology here centering on exploiting instability has allowed us to form a bulk $\mathrm{Mg}, \mathrm{Fe}$ nitride solid solution with cubic rocksalt symmetry which has already been targeted as technologically important for the endmembers $\mathrm{MgN}$ and $\mathrm{FeN}^{[13,14,24]}$, but is not accessible to them. The approach can be employed for synthesis of a broader range of normally unformable solid solutions, from nitrides to hydrides, leading to new materials and phase diagrams. These developed diagrams by judicious use of pressure, can then contain sought crystal symmetries and tunable properties, even when these are not stable at the endpoints, unlike the conventional case where the endpoints are stable. ${ }^{[1]}$ Evidence that access to intermediate solid solutions is of great benefit is seen through exploitation of ambient occurrence of a particular form of brass and mullite widely used in mechanical and thermal applications. ${ }^{[9,25]}$

Rocksalt $\mathrm{Mg}_{\mathrm{x}} \mathrm{Fe}_{1-\mathrm{x}} \mathrm{N}$ is also of considerable crystal chemical importance with regards our planet's interior, not least because it is isostructural to $\mathrm{Mg}_{\mathrm{x}} \mathrm{Fe}_{1-\mathrm{x}} \mathrm{O}$ which is our planet's most abundant rocksalt structure, comprising $20 \%$ by volume of the lower mantle. ${ }^{[3]}$ Hence its static and shock compressional behavior and properties, are of high value. ${ }^{[26]}$ The relationship between composition and these properties is significant. For this magnesium iron oxide, one can only vary the cation stoichiometry to investigate compositional changes, whereas for the magnesium iron nitride one can also vary the anion content. ${ }^{[27]}$ Linked to this, the high pressure and temperature behavior of magnesium iron nitride is also of specific geochemical and geophysical interest based on several recent studies on enhanced nitrogen partitioning in the deep Earth. ${ }^{[28]}$ Hence, the findings here are a foundation for addressing what ripple effect the presence of light elements can have on alloying of light metals, including $\mathrm{Mg}$, with $\mathrm{Fe}$ on core composition and density.

Finally, we suggest that the materials chemistry result here, where the sought bulk rocksalt structure is not achieved by the two endmembers in isolation, but only in the context of each other, has some analogy to mathematical developments applied in game theory, ${ }^{[29]}$ where an optimal result is reached only when players do what is best for them and for the other member. As materials chemistry experiment and theory advance and our materials database increases, this latter type of formalism can also become a tool in predicting materials behavior and outcome.

\section{Acknowledgements}

The TEM facility in Lille (France) is supported by the Conseil Regional du Nord-Pas de Calais and the European Regional Development Fund. We gratefully acknowledge the EU framework CALIPSO for support (Deutsches Elektronen Synchrotron), the EU "Research Infrastructures: Transnational Access" Programme (Bayerisches Geoinstitut) as well as proposal MA712 (European Synchrotron Radiation Facility). We also thank Laurence Nigay, Javier Ruiz-Fuertes, Beate Schwager, Reiner Ditz, Andy McGaff, Niall Russell, Paul Johnson, Christian Lathe, Godfrey J. Fitton, Ahmed Addad, Nicola Cayzer, Chris Hayward, Colin Humphreys, Michael Hall, as well as Lumilog company. 
Keywords: reactivity $\cdot$ materials synthesis, nitrides $\cdot$ pressure and temperature $\cdot$ precession electron diffraction $\cdot$ angle dispersive X-ray diffraction

[1] a) H. Saitoh, W. Utsumi, H. Kaneko, K. Aoki, Japanese J. Appl. Phys Pt2-Lett \& Express Lett., 2004, 43, L981-L983; b) D. M. Roy, R. E. Barks, Nature-Physical Sci., 1972, 235, 118-119; c) H. Stöhr, W. Z. Klemm, Z. Anorg. Allgem. Chem., 1939, 241, 305-323.

[2] E. Gibney, Nature 2014, 514, 152-153.

[3] C. I. Bovolo, Phil. Trans. Trans. Royal Soc. A 2005, 363, 2811-2835.

[4] W. D. Callister, Materials Science and Engineering: An Introduction, 6th ed.; John Wiley \& Son New York, 2003.

[5] R. H. Taylor, S. H. Curtarolo, G. L. W. Hart, Phys. Rev. B. 2011, 84, 084101-1-084101-17.

[6] a) B. L. Mordike, T. Ebert, Mat. Sci. Eng. A 2001, 302, 37-45; b) S. R. Agnew, J. F. Nie, Script. Mat. 2010, 63, 671-673

[7] S. Zheng, K. Wang, A. B. Oleshko, A. B. Leonid, J. Phys. Chem. C 2012, 116, 21277-21284.

[8] a) C. Hampp, B. Ullmann, J. Reifenrath, N. Angrisani, D. Dziuba, D. Bormann, J. M. Seitz, A. Meyer-Lindenberg, Adv. Eng. Mat. 2012, 14 B28-B37; b) C. Castellani, R. A. Lindtner, P. Hausbrandt, E. Tschegg, S E. Stanzl-Tschegg, G. Zanoni, S. Beck, A. M. Weinberg, Act. Biomat 2011, 7, 432-440.

[9] T. Massalski, Binary Alloy Phase diagrams, 2nd ed.; Massalski, T., Ed.; ASM: Ohio, 1990; Vol. 2.

[10] a) D. Errandonea, Y. Meng, D. Hausermann, T. Uchida, J. Phys. Cond. Matt. 2003, 15, 1277-1289; b) E. Huang, W. A. Bassett, P. L. Tao, J Geophys. Res. 1987, 92, 8129-8135.

[11] N. Dubrovinskaia, L. Dubrovinsky, I. Kantor, W. A. Crichton, V. Dmitriev, V. Prakapenka, G. Shen, L. Vitos, R. Ahuja, B. Johansson, I. A. Abrikosov, Phys. Rev. Lett. 2005, 95, 245502-1 - 245502-4.

[12] G. Serghiou, C. L. Guillaume, A. Thomson, J. P. Morniroli, D. J. Frost, J. Am. Chem. Soc. 2009, 131, 15170-15175.

[13] H. R. Soni, V. Mankad, S. K. Gupta, P. K. Jha, J. Alloys Comp. 2012 522, 106-113.

[14] A. Droghetti, N. Baadji, S. Sanvito, Phys. Rev. B 2009, 80, 235310-1235310-5.

[15] a) M. Hasegawa, T. Yagi, J. Alloys Comp. 2005, 403, 131-142; b) G. Serghiou, G. Ji, N. Odling, H. J. Reichmann, D. J. Frost, J. P. Wright, High Pressure Res. 2015, 35, 28-36.

[16] S. R. Roemer, Dorfler, T.; Kroll, P., W. Schnick, Phys. Stat. Sol. B 2009, 246, 1604-1613.

[17] R. Niewa, D. Rau, A. Wosylus, K. Meier, M. Hanfland, M. Wessel, R. Dronskowski, D. A. Dzivenko, R. Riedel, U. Schwarz, Chem. Mat. 2009 21, 392-398.

[18] a) C. D. Gelatt, A. R. Williams, V. L. Moruzzi, Phys. Rev. B 1983, 27 , 2005-2013; b) C. Stampfl, W. Mannstadt, R. Asahi, A. J. Freeman, Phys. Rev. B, 2001, 63, 155106-1 -155106-11; c) B. Eck, R Dronskowski, M. Takahashi, S. Kikkawa, J. Mater. Chem. 1999, 9 1527-1537

[19] B. Alling, Phys. Rev. B 2014, 89, 085112-1-085112-9.

[20] B. Alling, C. Hoglund, R. Hall-Wilton, L. Hultman, Appl. Phys. Lett. 2011, 98, 241911-1-241911-3.

[21] a) D. J. Frost, B. T. Poe, R. G. Tronnes, C. Liebske, A. Duba, D. C. Rubie, 2004, Phys. Earth Plan. Sci. Int., 143-144, 507-514; b) G. Serghiou, G. Ji, M. Koch-Müller, N. Odling, H. J. Reichmann, J. P. Wright, P. Johnson, Inorg. Chem. 2014, 53, 5656-5662 ; c) J. P. Morniroli, G. Ji, D. Jacob, Ultramicroscopy 2012, 121, 42-60 ; d) G. Ji, J. P. Morniroli, G. J. Auchterlonie, J. Drennan, D. Jacob, Ultramicroscopy 2009, 109, 1282-1294; e) R. Boehler, H. G. Musshoff, R. Ditz, G. Aquilanti, A. Trapananti, A. Rev. Sci. Instr. 2009, 80, 045103-10.45103-6 ; f) A. J. McGaff, G. Serghiou, D. J. Frost, High Press. Res. 2008, 28, 491-495; g) G. B. M. Vaughan, J. P. Wright, A. Bytchkov, H Rossat, I. Gleyzolle, I. Snigireva, A. Snigirev, J. Synchr. Radiat. 2011, 30, 125-133; h) C. L. Guillaume, G. Serghiou, A. Thomson, J. P. Morniroli, D. J. Frost, N. Odling, C. E. Jeffree, Inorg. Chem. 2010, 49 8230-8236.

[22] D. Frei, A. Liebscher, G. Franz, B. Wunder, S. Klemme, J. Blundy, Contrib. Mineral. Petrol., 2009, 157, 473-490.
[23] G. Serghiou, N. Odling, R. Hunter, A. Abbie, B. Armstrong, C. Lathe, High Pressure Res. 2014, 34, 176-183.

[24] a) W. R. L. Lambrecht, M. S. Miao, P. Lukashev, J. Appl. Phys. 2005 97, 10D306-1-10D306-3; b) B. Bialek, J. Lee, I. Solid State Comm. 2010, 150, 2138-2141.

[25] F. J. Klug, S. Prochazka, R. H. Doremus, J. Am. Ceram. Soc. 1987, 70, 750-759.

[26] a) H. Marquardt, S. Speziale, H. J. Reichmann, D. J. Frost, F. R. Schilling, E. J. Garnero, Science 2009, 324, 224-226; b) R. S. McWilliams, D. K. Spaulding, J. H. Eggert, P. M. Celliers, D. G. Hicks, R. F. Smith, G. W. Collins, R. Jeanloz, Science 2012, 338, 1330-1333.

[27] C. Stampfl, A. J. Freeman, Phys. Rev. B 2003, 67, 064108-1-064108-7.

[28] B. Marty, Earth Planet. Sci. Lett. 2012, 313, 56-66.

[29] J. F. Nash, Proc. Nat. Acad. Sci. Am. 1950, 36, 48-49. 


\section{COMMUNICATION}

Exploiting instability: Using pressure a mutually beneficial avenue is created 1 for otherwise unstable bulk endmember cubic nitrides to be stabilized upon heating 2 in a novel cubic solid solution $\mathbf{3}$ of crystal chemical, technological and planetary science importance.

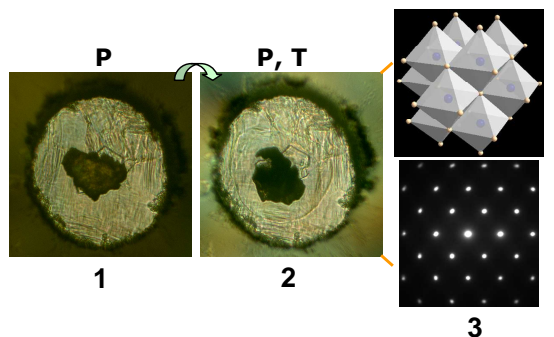

G. Serghiou, G. Ji, N. Odling, H. J. Reichmann, J. -P. Morniroli, R. Boehler, D. J. Frost, J. P. Wright, B. Wunder

Page No. - Page No.

Creating Reactivity with Unstable Endmembers using Pressure and Temperature: Synthesis of bulk cubic $\mathrm{Mg}_{0.4} \mathrm{Fe}_{0.6} \mathrm{~N}$ 